\title{
Learning vocabulary for IELTS Academic Reading: An evaluation of some pedagogical materials
}

\author{
Marta Serrano van der Laan \\ marta.serrano.vanderlaan@gmail.com \\ Universidad Nacional de Educación a Distancia (UNED), Spain
}

\begin{abstract}
A large receptive vocabulary could have a significant impact on scores in the IELTS Academic Reading test. However, the lack of official information about vocabulary in this test raises questions regarding how lexis is selected and approached in existing IELTS training materials. This paper evaluates three books issued by leading ELT publishers to assess how far they effectively help learn vocabulary for the Academic Reading test. First, the lexis in the test is identified based on what can be gleaned from official information and available research. Then, the three books are evaluated using a checklist of criteria relevant to the acquisition of this lexis. The results suggest that the materials investigated may not contribute enough towards the acquisition of vocabulary useful for success in the Academic Reading test. This paper offers some important insights into some shortcomings of current IELTS training materials and points to ways of surmounting them.
\end{abstract}

Keywords: IELTS; reading; materials; evaluation; acquisition; vocabulary

\section{INTRODUCTION}

Passing IELTS Academic with an overall score of 7.0 (C1 on the Common European Framework of Reference (CEFR)) is a goal for many students worldwide. The IELTS (International English Language Testing System) Academic test is used by universities worldwide to determine whether candidates' proficiency in English will enable them to study in English-medium environments. An IELTS score above 6.0 is usually required for admission.

\section{I.1. A strategy for success in IELTS}

Many candidates find themselves in the need of attaining an overall IELTS score that is above their current level of proficiency, in a limited period of time dictated by university application procedures. Candidates also tend to approach the exam with different levels of ability in the four language skills. As the overall IELTS score is the average of the scores attained in each of the four discrete skills tests that make up the 
exam, good results in one or more tests can significantly raise overall exam scores. Thus, it can be a useful strategy to dedicate efforts to improving results in the test in which success is most likely. One of the tests in which candidates attain their highest scores, regardless of overall level (IELTS, 2020), is the Academic Reading (AR) paper. In AR, candidates must answer 40 questions about three long, real-world texts in one hour.

One way of improving reading scores could be by developing receptive, or recognition, vocabulary knowledge. Research has established the key role of vocabulary knowledge in reading (Laufer \& Ravenhorst-Kalovski, 2010; Nation, 2013; Schmitt, Jiang \& Grabe, 2011) and relevant literature suggests that vocabulary can be learnt quite quickly for receptive purposes (Nation, 2013; Sökmen, 1997; Webb \& Nation, 2017). Although not specifically assessed, knowledge of vocabulary seems to play a key role in the AR test. A close inspection of published practice tests ${ }^{i}$ reveals that answering the majority of the questions requires the recognition of synonymy and paraphrase. Additionally, the length and density of the texts mean that a lack of vocabulary may constitute a major handicap in this high-stakes language examination. Therefore, increasing receptive vocabulary size could positively impact reading scores and as a consequence overall scores could be raised.

\section{I.2. Framing the problem}

In order to increase the size of candidates' receptive vocabulary for success in IELTS $\mathrm{AR}$, it is necessary to know what vocabulary is involved. However, guidance as to the vocabulary to study for IELTS AR is scarce. The test is not based on a set vocabulary syllabus, and the IELTS consortium divulges little information regarding vocabulary useful towards passing the test successfully. At the same time, existing literature on vocabulary in IELTS mainly regards the IELTS Speaking and Writing tests. At the same time, IELTS coursebooks usually include sections on vocabulary, and some textbooks dedicated to vocabulary for IELTS are also available. Given the dearth of research and information about vocabulary in this test, it is unclear how these materials are informed. Furthermore, recent literature suggests that coursebooks often seem to 
lack a solid grounding in principle and familiarity with state-of-the-art research on vocabulary (Schmitt, 2019).

\section{I.3. Aim and scope}

This paper critically evaluates three books that claim to help learners acquire vocabulary towards IELTS. The aim of the study is to understand whether these books effectively provide exam candidates with the vocabulary they need for success in the AR test. To this purpose, a checklist was developed and used to evaluate how far the books address the features of AR vocabulary that can be gleaned from official information and available literature. The checklist also examines the books' grounding in established pedagogical principle

The outcome of the evaluation suggests that the books examined fall short of their claims due to their unsatisfactory grounding in research and pedagogical principle. This paper provides some important insights into the limitations of current vocabulary study materials for IELTS. The results presented here may usefully inform future IELTS vocabulary learning materials.

\section{THEORETICAL BACKGROUND}

Although it is well-researched that vocabulary is crucial for reading (Alderson, 2000; Schmitt, Jiang \& Grabe, 2011), this paper evidences that only a surprisingly small body of literature is available on vocabulary in the IELTS AR test. Nonetheless, relevant information about the lexis in the test can also be learnt from some studies on other aspects of IELTS. This section provides an overview of research that provides key insights into vocabulary in IELTS AR and that underpins the present investigation.

\section{II.1. Vocabulary and reading}

Research indicates that reading comprehension is dependent on high percentages of vocabulary knowledge (Hu \& Nation, 2000; Milton, 2009). In fact, Alderson (2000, p.35) asserts that vocabulary knowledge is "the single best predictor of text 
comprehension" among the many other variables that are also involved. Knowledge of vocabulary applied successfully to reading implies the possession of a large receptive lexicon, that is, a strong form-meaning knowledge (Schmitt, 2014). As aspects of deeper word knowledge such as morphology or collocation are provided or clarified by the context, depth of vocabulary knowledge may be of less relevance (Schmitt, 2014). However, phonological knowledge may be highly relevant to reading as phonological memory may play a greater role than has previously been considered (Lin, 2019; Milton, 2009; Walter, 2008) Awareness of derivation may also have a bearing on reading, as research indicates that knowledge of a stem word is no guarantee of recognition of its derived forms (Schmitt \& Zimmerman, 2002).

A further element of vocabulary knowledge that affects reading is formulaic language, that is, the tendency of vocabulary to take the shape of phraseological units of two or more words, rather than consist in single words connected syntactically (Schmitt, 2013). Martinez and Murphy (2011) showed that formulaic units can be the source of incomprehension, as they are often semantically opaque and readers may not recognize them as units of meaning. Thus, knowledge and awareness of formulaic language is key to successful reading.

It would seem, therefore, that a good receptive knowledge of vocabulary should be highly useful towards passing the IELTS AR test. This lexicon should be composed of key individual words and opaque formulaic or multiword units (MWUs) (Martinez and Schmitt 2012). This strong sight knowledge should be supported by some aspects of deeper vocabulary knowledge such as phonology and morphology.

\section{II.2. Vocabulary and IELTS AR}

Vocabulary in IELTS has received little attention overall in the literature to date. However, a few specific studies are available. Bax (2013) found that successful AR candidates were more lexically proficient and better able to match words in the questions with synonyms in the text than less successful candidates. Milton, Wade \& Hopkins (2010) correlated IELTS scores to vocabulary size test results, finding a very strong relationship between receptive vocabulary size and the AR test. Moreover, they found that $48 \%$ of variance in scores in this test can be explained by orthographic, or 
sight, vocabulary size, making this the possibly most determining factor for success in the AR test. This suggests that attention to orthographic knowledge of vocabulary is highly relevant for the AR test.

Relevant insights about vocabulary in IELTS AR can also be gained from work not specifically investigating vocabulary. In their study of how AR test materials are developed, Green and Hawkey (2011) show that source texts for AR reading passages tend to be more general than academic. Even after adaptation to the IELTS test format, the texts seem uncharacteristic of standard academic texts, as they contain larger than typical percentages of high-frequency vocabulary (Green \& Hawkey, 2011; Weir Hawkey, Green, Unaldi \& Devi, 2009). This suggests that focusing strictly on academic vocabulary is not useful when approaching the AR test. In fact, it can be deduced from Schmitt and Schmitt (2014) that concentrating on general high-to mid-frequency lexis would be more appropriate, as their seminal paper shows that this vocabulary tends to be prevalent in non-specialist, university-level texts. The relevance of these frequency levels is corroborated by the findings in Drummond (2018), which reveal that candidates attaining an overall IELTS score of 6.5 to 7.0 may have a vocabulary size that affords them approximately 90\% text coverage. According to Schmitt and Schmitt (2014), such coverage is granted by knowledge of the first 3- to 4000 most frequent words in English, i.e. high- and early mid-frequency vocabulary.

\section{II.3. Vocabulary learning and published pedagogical materials}

Classroom experience and research show that many learners struggle to acquire substantial amounts of vocabulary, even over time (Henriksen and Danelund 2015), and often have a poor knowledge of high-frequency vocabulary (Lawley 2010). One reason for this situation may lie in the shortcomings of published learning materials. In his recent research agenda, Schmitt (2019) lists investigating why these materials so often do not reflect current vocabulary teaching principles. To mention just a few of the numerous studies that reveal such deficiencies, Lawley (2010) and Acosta Moncada et al. (2016) found that the coursebooks they analyzed dedicated a surprising amount of space to less frequent lexis, to the detriment of high-frequency vocabulary. O'Loughlin (2012) and Demetriou (2017) also found that extensively used coursebooks contained 
little frequent vocabulary and overall approached it unsystematically, often only providing one encounter with the target items.

Given these premises, prospects appear inauspicious also for published vocabularylearning materials aimed at IELTS. A few dedicated books are currently available on the market, as are some IELTS training materials that contain a section on vocabulary. These materials would seem to merit close inspection for a number of reasons. Firstly, they may effectively be the only existing guides to learning vocabulary for IELTS, given the dearth of research and information available on vocabulary and the exam. At the same time, this very lack of information gives rise to questions regarding how the pedagogical choices in these books are informed. Moreover, assessment materials such as those mentioned above outline potential weaknesses that should be verified also in these materials.

\section{METHODOLOGY}

This investigation sets out to answer the following research question: Are existing published vocabulary learning materials for IELTS useful towards increasing receptive vocabulary size with a view to successfully passing the AR test? In this section the methodology and the materials used to answer this question are described.

\section{III.1. The books evaluated}

Three books were selected for the present investigation (See Table 1). Four main criteria were used to select these books. Firstly, all three were issued by well-established English Language Teaching (ELT) publishers. This suggests that they are pedagogically sound and developed by experts in the field and therefore valid materials for IELTS candidates. Secondly, the presence on an international level of all three publishers means that the books are available to students in many countries and that it is therefore useful to examine their content. Thirdly, the three books have good face-value, in that they look clearly structured, cover a variety of IELTS topics, seem to present and practice vocabulary in contexts and exercises that are relevant to the exam, and provide an array of apparently useful ancillary material such as vocabulary lists, revision tests 
and exam tips. A final criterion for selecting these books for evaluation was that they seem to be aimed at a target level of IELTS 6.0 and above, which tend to be the scores from which IELTS is accepted in university application processes around the world, thus making the books relevant to IELTS candidates.

Table 1. The books evaluated.

\begin{tabular}{|c|c|c|c|c|}
\hline Title & Authors & Publisher & $\begin{array}{c}\text { Year of } \\
\text { publication }\end{array}$ & $\begin{array}{c}\text { Referred to in } \\
\text { text as }\end{array}$ \\
\hline $\begin{array}{c}\text { Vocabulary for } \\
\begin{array}{c}\text { IELTS. Self-study } \\
\text { vocabulary } \\
\text { practice }\end{array}\end{array}$ & Cullen, P. & $\begin{array}{c}\text { Cambridge } \\
\text { University Press }\end{array}$ & 2008 & VFIS \\
\hline $\begin{array}{c}\text { Focusing on } \\
\text { IELTS Reading } \\
\text { and Writing skills } \\
\text { (2nd ed.) }\end{array}$ & $\begin{array}{c}\text { Lindeck, J., } \\
\text { Greenwood, J., \& } \\
\text { O'Sullivan, K. }\end{array}$ & $\begin{array}{c}\text { Macmillan } \\
\text { Education } \\
\text { Australia }\end{array}$ & 2011 & FIRW \\
\hline $\begin{array}{c}\text { Vocabulary for } \\
\text { IELTS }\end{array}$ & Williams, A. & Collins & 2012 & VFI \\
\hline
\end{tabular}

All three books are directed at both IELTS Academic and IELTS General Training. VFIS (Cullen, 2008) and VFI (Williams, 2012) approach the target vocabulary topically, rather than by individual test. The items are presented and practiced in different exam-type contexts throughout the units, but no indication is provided as to which items or learning strategies might be specifically useful for each of the four different tests in the exam. FIRW (Lindeck, Greenwood \& O'Sullivan, 2011) is aimed at developing reading and writing skills for IELTS. Vocabulary is dealt with in two brief subsections in the unit on reading, where some suggestions are made about identifying and learning useful lexis, but no specific words are taught.

VFIS (Cullen, 2008) teaches about 1,211 lexical items including MWUs, organized into twenty topic-based units, with a test every five units. Lists of all the target items in each unit are provided at the back of the book. The vocabulary is taught through a variety of exercises including exam-type tasks, and listening and reading activities. A further five units close the book and focus on vocabulary learning skills, and on vocabulary for the Writing tests. The book boasts the label 'CEF (Common European Framework) B2$\mathrm{C} 1$ ', but it is not clear whether these are starting-out or target levels. 
VFI (Williams, 2012) covers about 277 different words through 18 topic-based units, with two revision units. The input does not include MWUs, and a complete word list is not supplied. By contrast, the book provides a list of common collocations for most of the target vocabulary. Each input unit focuses on 14-15 words connected to the unit topic. The target words are presented at the beginning of every unit using a dictionaryentry format for each word, providing part of speech, a definition and one or two example sentences. The subsequent sections of each unit practice these words through a variety of exercises, including listening, reading and exam-type tasks. The book targets students at an IELTS level of 5.0 - 5.5 who are aiming at a score of 6.0+.

FIRW approaches vocabulary for the Reading tests in two subsections (Lindeck, et al., 2011). Building up your vocabulary (pp.43-44) offers some brief suggestions on how to learn vocabulary in general and what type of lexis to look out for. In Identifying how words relate to each other (pp.44-47) learners are advised to notice relationships between words such as hyponymy, meronymy and collocation. The aim of these subsections is therefore not to teach a specific list of words, but rather to outline some useful strategies to learn vocabulary for IELTS Reading. No level is specified, but the presence of lengthy explanations and the choice of language used seem to target students beyond an intermediate level of proficiency.

\section{III.2. The checklist}

A simple checklist was developed to analyse the usefulness of the three books towards learning vocabulary that will help pass the AR test at a band level above 6.0 (See Table 2).

Table 2. Checklist for evaluation

\section{CHECKLIST}

1. Does the book teach the $1-8000$ most frequent words in English, including multiword units (MWUs)?

2. Is the vocabulary-learning program clearly defined?

3. Is a strong form-meaning knowledge developed?

4. Is morphology addressed?

5. Is phonology addressed?

6. Is synonymy and antonymy addressed? 
7. Are clear explanations provided regarding how to use the book?

8. Is feedback provided?

9. Is repetition facilitated and encouraged?

10. Are vocabulary learning strategies suggested?

The checklist takes inspiration from materials analyses such as Tomlinson and Masuhara (2013), Tomlinson (2010), and Reinders and Lewis (2006) and the questions are grounded in the following pedagogical and theoretical principles:

- $\quad$ frequency should be a key consideration when selecting vocabulary (Nation, 2013; Schmitt, 2008).

- $\quad$ vocabulary does not only involve individual words (Martinez \& Schmitt, 2012)

- $\quad$ receptive vocabulary knowledge includes morphological and phonological awareness (Walter, 2008; Gardner, 2013)

- learners need to be aware of the dimensions of the task ahead in order to set targets and plan their work (Dörnyei, 2001; Little, 2003; Schmitt 2008)

- $\quad$ autonomous learning strategies need to be fostered as the classroom typically does not afford sufficient time to deal with the amount of learning required (Webb \& Nation, 2017).

\section{III.3. Procedure}

The target words in VFIS (Cullen, 2008) are listed at the back of the book, while in VFI (Williams, 2012) they are at the beginning of each unit. These words were counted using the Microsoft Word word count tool in order to determine the books' learning load. As this tool cannot identify formulaic units as single lexical items, the components of the phrases and two-word compounds in VFIS (Cullen, 2008) were counted as individual words. This was not considered a miscount, as many of these components are also dealt with individually in the books. Furthermore, many of the formulaic units 
covered are semantically transparent, making it useful to understand their individual components. Nonetheless, the phrases and compounds were also counted as individual units, totalling 300 .

In order to establish the levels of frequency of the vocabulary in VFIS (Cullen, 2008) and VFI (Williams, 2012), all the words were processed through the frequency analysis tool Compleat Web VP BNC-COCA 1-25 (Cobb, n.d.). This web tool matches the words inputted to corpus-based frequency lists, identifying the level of frequency of each word. Some of the words used as examples in FIRW (Lindeck et al., 2011) were also profiled on this tool. The phrases in VFIS (Cullen, 2008) were checked manually against the PHRASE list (Martinez \& Schmitt, 2012).This is a list of the 505 most frequent semantically non-transparent MWUs in English. The aim was to assess the usefulness of the phrases included, given the relevance of frequency to vocabulary learning. The results and implications of this frequency profiling are discussed in Section IV below

\section{THE EVALUATION: RESULTS AND DISCUSSION}

Having examined the books known as VFIS (Cullen, 2008), VFI (Williams, 2012) and FIRW (Lindeck et al., 2011), the results obtained can be observed in Table 3 below.

Table 3. Results of the evaluation.

\begin{tabular}{|c|c|c|c|}
\hline & $\begin{array}{l}\text { VFIS } \\
\text { (Cullen, } \\
\text { 2008) }\end{array}$ & $\begin{array}{l}\text { FIRW } \\
\text { (Lindeck et } \\
\text { al., 2011) }\end{array}$ & $\begin{array}{c}\text { VFI } \\
\text { (Williams, } \\
\text { 2012) }\end{array}$ \\
\hline $\begin{array}{l}\text { 1. Does the book teach the } 1-8000 \text { most frequent } \\
\text { words in English, including multiword units } \\
\text { (MWUs)? }\end{array}$ & $x$ & $x$ & $x$ \\
\hline $\begin{array}{l}\text { 2. Is the vocabulary-learning program clearly } \\
\text { defined? }\end{array}$ & $x$ & $x$ & $x$ \\
\hline 3. Is a strong form-meaning knowledge developed? & $x$ & $x$ & $(\sqrt{ })$ \\
\hline 4. Is morphology addressed? & $(\checkmark)$ & $(\checkmark)$ & $(\checkmark)$ \\
\hline
\end{tabular}


5. Is phonology addressed?

6. Is synonymy and antonymy addressed?

7. Are clear explanations provided regarding how to use the book?

8. Is feedback provided?

$\checkmark \quad(\checkmark)$

9. Is repetition facilitated and encouraged?

$(\checkmark)$

$x$

$(\checkmark)$

10. Are vocabulary learning strategies suggested?

$(\checkmark)$

$(\checkmark)$

$(\checkmark)$

\section{IV.1. Question 1: Does the book teach the $1-8000$ most frequent words in English, including MWUs?}

As argued above, the AR passages can be predicted to require knowledge of high- to mid-frequency vocabulary, i.e. the 8,000 most frequent words in English. Since research has established that language is highly formulaic, and that opaque formulaic units can challenge reading comprehension, knowledge of MWUs (Martinez \& Schmitt, 2012) at similar levels of frequency should also be necessary.

The vocabulary profiles of the words in VFIS and VFI show that they largely belong to the appropriate frequency range. However, the books only target a small number of vocabulary items. No explanation is provided as to the choice of these particular items, no reference is made to the (rest of the) 8,000 most frequent words in English, and the concept of frequency and its key role as identifier of usefulness (Schmitt, 2010) is not mentioned.

FIRW indirectly refers to frequency by dividing vocabulary into versatile words (Lindeck et al., 2011, p.43) which "can be used in many different contexts", and specific words (Lindeck et al., 2011, p.43) "[of] very limited use, as they are usually used in one field or context only". The vocabulary profile of the example versatile words reveals that they fall into the 1-5k range, i.e. high- to mid-frequency according to Schmitt and Schmitt (2014). Thus, versatile would seem a suitable name for these words, and, given their relevance for the AR test, prompting students to learn them is clearly appropriate. However, learners are again not informed of how many versatile words there are in 
English, nor that research-based, pedagogical lists of versatile words exist and are available free of cost on the web, for example the frequency lists published on Compleat Lextutor (n.d.).

VFIS (Cullen, 2008) includes 50 MWUs, and VFI (Williams, 2012) none. Of the MWUs in VFIS (Cullen, 2008), only 15 appear in the PHRASE list (Martinez \& Schmitt, 2012). Why such a large amount of low-frequency phrases are included is unclear, particularly as high frequency formulaic units are often poorly known even at more advanced levels (Martinez \& Murphy, 2011). FIRW (Lindeck et al., 2011) touches on formulaic language in the section on collocation, which is part of a larger section discussing word relationships. Being able to identify these is presented as an important reading skill. Collocations are initially approached as a two-word pair phenomenon, with examples such as ask a question, interested in (Lindeck et al., 2011, p.47). Subsequently, formulaic units, such as hold the key or facing stiff competition, are shown as further examples of collocation (Lindeck et al., 2011, p.47). Given their semantic opacity, these phrases qualify as MWUs and could therefore more profitably approached as units of meaning rather than as a sequence of related words (Martinez \& Schmitt, 2012). No distinction is made between the two types of formulaic unit and no indication is given as to which might be more relevant to learn for reading purposes (i.e. MWUs).

\section{IV.2. Question 2: Is the vocabulary-learning programme clearly defined?}

Setting goals is key towards ensuring a principled and systematic learning program,e (Nation, 2013), determining the scope of the task (Schmitt, 2008), developing and maintaining motivation (Dörnyei, 2001), and supporting autonomous learning (Little, 2003). VFIS (Cullen, 2008) and VFI (Williams, 2012), however, outline their vocabulary-learning programmes only in very broad terms. VFIS "aims to extend and improve the accuracy of your vocabulary and help you prepare for the IELTS test" (Cullen, 2008, p.4), while VFI claims to help "improve your vocabulary when preparing for the IELTS examination" (Williams, 2012, p.4). Close inspection of the contents reveals that neither book explicitly states exactly how many words they teach nor why these words should be learnt. In fact, in the two chapters on vocabulary learning skills 
(21 and 22), VFIS suggests acquiring further, non-specified vocabulary beyond the book's word list (Cullen, 2008). Thus, the dimensions and the exact composition of the learning programme are not clear.

FIRW does not quantify vocabulary learning aims. Instead, learners seem to be invited to build up an IELTS lexicon through reading generally (Lindeck, et al., 2011) p.44). This seems an impractical suggestion for time-strapped IELTS candidates, as research has amply proven that incidental learning of vocabulary through reading yields far smaller and slower results than intentional word learning (File \& Adams, 2010; Laufer, 2003; Webb \& Nation, 2017). IELTS candidates cannot afford to spend time on undefined learning programmes with no clear predicted outcome.

A further problem regarding the definition of the learning programme in these books is that learners are not advised to identify where their vocabulary knowledge intersects with the books' syllabuses. Only advanced learners are advised to begin study of each block of five units in VFIS (Cullen, 2008) by taking its corresponding vocabulary test. The assumption seems to be that learners at lower levels are unlikely to be familiar with most or any of the words in the book. This is not necessarily the case: research suggests that learners do not acquire vocabulary linearly, but rather according to their needs and to the language they are exposed to (Schmitt, 2019). As discussed above, textbooks often focus more on low-frequency vocabulary than on high-frequency lexis (Lawley, 2010; O'Loughlin, 2012). Thus, determining their distance from the target is useful for all learners. However, to achieve this, they must be informed of the dimensions of the task and be provided with the means to assess their position with respect to the target. None of the books afford this support satisfactorily.

\section{IV.3. Question 3: Is a strong form-meaning knowledge developed?}

Schmitt (2014) claims that a receptive lexicon useful for reading involves a strong formmeaning knowledge. To this purpose, learners need to recognize word form and connect it with its meaning, and re-encounter target items repeatedly at spaced intervals (Webb \& Nation, 2017). Recent literature consistently recommends the use of flashcards to develop form-meaning knowledge (Gardner, 2013; Nation, 2013, Webb \& Nation, 2017), as cards allow manipulation such as randomization and reshuffling (Ballance \& 
Cobb, 2018). Bilingual L1-L2 word cards have been found to be particularly conducive to learning (Schmitt, 2008, Webb \& Nation, 2017).

None of the books in this evaluation focuses explicitly on developing form-meaning knowledge nor mention bilingual word pair learning nor flashcards. VFI (Williams, 2012) can be seen to facilitate form-meaning knowledge in that it presents the target words in the dictionary-entry format of word plus brief definition, but not so repeated retrieval and manipulation. VFIS (Cullen, 2008) prefers a word list, without providing meaning or guidance for learning it, and in spite of the risk of serial learning induced by the list format (Nation and Webb 2011). FIRW (Lindeck et al., 2011) might have been ideally positioned to advise students to use flashcards, as its vocabulary section consists in suggestions for learning vocabulary. It does not mention flashcards, however, and instead discusses guessing from context and dictionary use to discover meaning, which are reading skills rather than ways to learn vocabulary.

\section{IV.4. Question 4: Is morphology addressed?}

Awareness of morphology can help increase vocabulary size and the recognition of lexis (Gardner, 2013, p.131). Awareness of derivation is particularly relevant for reading, as research has shown that derived forms may not be understood, despite knowledge of stem forms (Schmitt \& Zimmerman, 2002). Morphology is dealt with in a variety of ways in the three books, although overall a lack of underlying systematicity is apparent. VFIS (Cullen, 2008) draws attention to aspects of morphology in page margin notes randomly placed through the units. For example, "prefixes can help you work out the meaning of unknown words" (Cullen, 2008, p.113). Students are invited to find derivations for words learnt and to record them in a table, and word-family table completion exercises appear at different points in the book. The word list includes derived forms for at least 112 stem words, but attention is not specifically drawn to this relationship, and it is not clear why these particular words and forms have been selected and not others.

VFI (Williams, 2012) provides inflections for the nouns and verbs covered in every unit, and also dedicates some attention to affixation via exercises and Exam tip boxes in page margins. However, the importance of these concepts for vocabulary development 
is not explicitly addressed. By contrast, FIRW (Lindeck et al., 2011) mentions the importance of affixation for guessing the meaning of unknown words. Unfortunately, prefixes are defined as "usually show[ing] the opposite or a contrast" (Lindeck et al., 2011, p.51), while suffixes are defined as "chang[ing] the word form" (Lindeck et al., 2011, p.51). These are, to say the least, incomplete and infelicitous explanations.

Overall, morphology is addressed to some extent in all three books, but without the systematic, explicit attention it requires.

\section{IV.5. Question 5: Does the book address phonology?}

Phonology is usually assumed to regard speaking and listening. This may explain why it is not addressed in FIRW (Lindeck et al., 2011), which focuses on reading and writing. However, some research suggests that phonology is highly relevant for reading, particularly for speakers of languages with alphabetic orthography. Walter (2008) argues that words read are stored first in the phonological loop rather than in the visuospatial sketchpad. Milton (2009) claims that it is strongly possible that the phonic representation of words is far more significant than their written form for the mental lexicon of most learners. Furthermore, it seems that it is the specific prosodic features of formulaic sequences which identifies them as linguistic units, to the point that Lin (2019, p.90) suggests that they would be better treated as "strings of sounds rather than strings of words".

Of the three books, VFIS dedicates most attention to pronunciation, including one pronunciation exercise in each of twelve units, which focuses on individual sounds, minimal pairs and stress patterns. The exercises always have an audio component. Learning the pronunciation of a word is listed as one of the steps in the general wordlearning plan outlined in Unit 22, and the word list at the back of the book provides the phonemic transcription for each individual word, but not for the MWUs. This is unfortunate, as Lin (2012) suggests that learning MWUs as sound units facilitates the learning and retention of the phrases and can contribute towards greater reading fluency. VFI (Williams, 2012) only touches on pronunciation in Unit 4 (stress patterns), Unit 8 (/s/ vs /z/), Unit 12 ("problem consonants", p.53) and Unit 16 (/ə/). A brief exercise is included that uses the book CD. Phonemic transcriptions or audio tracks of the target 
words are not provided. Thus, phonology is addressed summarily in VFIS (Cullen, 2008), minimally in VFI (Williams, 2012) and not at all in FIRW (Lindeck et al., 2011).

\section{IV.6. Question 6: Is synonymy and antonymy addressed?}

Bax (2013) stressed the value of attending to synonymy when preparing for IELTS, and practice material ${ }^{\mathrm{i}}$ endorsed by IELTS reveals that recognition of synonymy is highly relevant in order to answer questions in the AR test. VFI (Williams, 2012) explicitly draws attention to synonymy in units 2 and 14 . However, work is limited to one or two exercises, with no suggestions for how to build up a lexicon of synonyms or what words to concentrate on. VFIS (Cullen, 2008) regularly includes exercises that require identifying synonyms in a text or finding synonyms for words extracted from a text, but never mentions the specific importance of synonymy for the AR test. By contrast, FIRW (Lindeck et al., 2011) dedicates a whole section to synonymy and antonymy, where it defines the concept and explains the importance of being able to identify synonyms and antonyms in text and questions in the AR test, and provides examples of both types of word relation. Prefixes are underlined as frequent identifiers of antonymy, but suffixes (e.g. useful-useless) are not mentioned. Techniques are not suggested for developing a lexicon of synomyms and antonyms, as could be keeping tables of word families, or making mindmaps, and this seems an opportunity missed in this guide to building up vocabulary for the AR test.

\section{IV.7. Question 7: Are clear explanations provided regarding how to use the book?}

Nation (2011) posits that the focus of a vocabulary learning programme should be more on learning than on teaching vocabulary. This suggests that self-study plays a major role in this learning process, also considering that classroom time is too limited to ensure large amounts of vocabulary learning (Webb \& Nation, 2017). In their list of features of good self-study materials, Reinders and Lewis (2006) include the need for clear explanations on how to use them. It therefore seems appropriate to critically assess whether, how and how much learners are guided in using the books investigated here. 
Both VFIS (Cullen, 2008) and VFI (Williams, 2012) provide detailed suggestions for how to work through the units, using the ancillary materials (word list, tests and reference section in VFIS; collocations list and revision units in VFI) and keeping a vocabulary notebook. FIRW (Lindeck et al., 2011), by contrast, limits instructions for using the book to one paragraph_where learners are advised to do all the exercises provided. They are also told that they can "easily select the particular sections to study based on [their] specific needs" (Lindeck et al., 2011, p.V). A useful improvement would be to supply tools to help learners identify these needs. However, this would only be helpful if clear vocabulary learning targets were identified previously, and this does not occur, as has been discussed with regard to question 2 above.

\section{IV.8. Question 8: Does the book provide feedback?}

Feedback is a key factor in learning, as it facilitates self-evaluation and fosters motivation (Dörnyei, 2001). In all three materials analyzed here, feedback can be obtained from the answer keys provided at the end of each book. FIRW (Lindeck et al., 2011) offers no further occasions for feedback, while in VFIS (Cullen, 2008) and VFI (Williams, 2012) many of the learning tips found in the units can be viewed as indirect feedback, as they can stimulate reflection. The five tests in VFIS (Cullen, 2008) and the two revision units in VFI (Williams, 2012) are further sources of feedback. Some check questions at the end of each unit, or a plan of expanded rehearsal (Schmitt, 2010) could be useful additions to develop the feedback features in these books.

\section{IV.9. Question 9: Is repetition facilitated and encouraged?}

Repeatedly meeting a new word strengthens knowledge of and about it (Nation, 2013; Webb \& Nation, 2017). Although there is no agreement in the literature as to how many revisitations of a lexical item are necessary in order to learn it (see Schmitt (2007) for some possible numbers of repetitions), systematic revision sessions are necessary, as research shows that forgetting begins shortly after the end of a learning session (Schmitt, 2007). 
Basic repetition tools are provided in VFIS (Cullen, 2008) in the shape of regularly spaced vocabulary tests -one test every five units, for a total of five tests- while VFI (Williams, 2012) provides two tests, after the first and last ten units. Aside from this, there are few further opportunities for revisiting vocabulary, as only a handful of target words ever appear more than once in these books. By contrast, revisiting vocabulary is recommended in the two-page how to use the book sections of both volumes, although no guidance is provided as to how or how often to do it. Repetition is neither mentioned nor facilitated in FIRW (Lindeck et al., 2011). It would therefore appear that the books investigated here do not offer sufficiently structured recycling programmes.

\section{IV.10. Question 10: Are vocabulary learning strategies suggested?}

Memorization and retrieval techniques play a key role in retention of vocabulary (Ellis, 2001). Moreover, research indicates that successful learners seem to use a variety of vocabulary learning strategies, and therefore explicit instruction of these techniques could be beneficial (Chacón-Beltrán, 2018). In Unit 22, VFIS (Cullen, 2008) proposes the following sequence of learning steps, illustrated with example words and exercises: find out the meaning and the different forms of a word, learn its pronunciation and how to spell it; use the word, remember the context, apply spelling rules (Cullen, 2008, pp.114-116). The book can therefore be said to provide a framework for learning the basic aspects of a word, i.e. form, meaning, and use. Curiously, the examples and exercises that illustrate each step do not use vocabulary taught in the book. This wordlearning plan could usefully be moved to the beginning of the book, focusing it on the book's word list, thus furnishing learners with a practical strategy for setting out to learn the target vocabulary. The plan should include concrete learning techniques for memorizing, retaining and retrieving the new vocabulary.

FIRW usefully suggests trying different strategies to decide which are more effective (Lindeck et al., 2011, p.43). Further useful suggestions are using target words in a written sentence, checking their pronunciation and then saying them out loud repeatedly, and learning to distinguish between frequent and less frequent words. Learners are also advised to guess meaning from context and check the accuracy of the guess at a later stage, which is again more of a reading strategy than a technique for 
"building up your vocabulary", as the section heading would have it (Lindeck et al., 2011, p. 43). Other essential word-learning methods are not mentioned, such as memorization and retrieval techniques. No activities for trying out the proposed techniques are included, and no tools are suggested that can help learners record, memorize and retrieve new vocabulary.

VFI (Williams, 2012) makes brief but frequent suggestions for vocabulary learning throughout the book in the 'Exam tip' boxes, such as studying example sentences or learning the different parts of speech of a new word. Curiously, here too the strategies are not applied to the vocabulary syllabus in the book, but seem to be aimed at a broader and undefined vocabulary learning program. The suggestions in the tip boxes might more usefully be related to the target vocabulary in the units, facilitating its learning, recycling and retrieval.

As can be seen, the learning strategies proposed in all three books are suitable for longterm study programs. This seems an impractical approach for IELTS materials, since studying for IELTS typically takes place within a short time span. Student life is articulated by a variety of short-term deadlines, such as those imposed by university application and admission procedures, which usually include presenting IELTS scores by a given date. The provision of a framework for short-term vocabulary learning would be desirable in materials that claim to prepare for IELTS. Such a framework could consist in the deliberate learning of form-meaning pairs from word cards and word lists. The literature shows that this is a highly effective way of quickly acquiring significant amounts of vocabulary, particularly if the word lists are bilingual (Elgort, 2011; Laufer \& Shmueli, 1997, Schmitt, 2008, Webb \& Nation, 2017).

\section{CONCLUSIONS}

This study set out to investigate whether three vocabulary learning books for IELTS issued by authoritative publishers could be considered effectively useful towards passing the AR test successfully. The outcome of the evaluation performed suggests the contrary. None of the books make a clear case as to what vocabulary is necessary for IELTS AR, nor how much of it can be learnt by using the materials. At the same time, the vocabulary addressed seems to be the result of an insufficiently informed and 
incomplete selection, as no mention is made of relevant frequency levels, target vocabulary size or text coverage afforded. Schmitt (2019) identified the need for current vocabulary materials to be more systematic and principle-based. He also pointed at the key role of materials writers as the most appropriate players to develop pedagogically sound vocabulary learning programmes, as teachers tend to be time-strapped and unable to keep up with state-of -the art research. The results of this study confirm Schmitt's research agenda and lay bare the urgent need for appropriate vocabulary materials for IELTS study.

This paper identifies relevant issues regarding vocabulary learning materials for IELTS, in particular the need for materials to use a principled approach, grounded in research. They also need to outline clear learning objectives based on the effective requirements of the exam. A limitation of this study is the lack of a more precise knowledge of the features of the vocabulary typical of AR texts. As an independent study not funded or endorsed by IELTS, access to authentic IELTS exam materials was impossible. Future research could usefully investigate a statistically significant sample of AR passages, making it possible to provide IELTS candidates with evidence-based vocabulary learning goals.

\footnotetext{
Notes

${ }^{\text {i }}$ Cambridge University Press publishes past IELTS papers on a more or less annual basis in their IELTS Practice Tests volumes. A practice test is also available on https://www.ielts.org/
}

\section{REFERENCES}

Acosta Moncada, M., Castro Donoso, J., Demarchi Gigogne, D., Jerez Escobar, M., Maltés Guajardo, J., Miranda Cuevas, P., Moraga Quiroz, C.P., \& Rojas Tello, M. (2016). Content analysis of students' English textbooks and curricula from the Chilean Ministry of Education in relation to vocabulary acquisition and language planning. Informe Final de Seminario de Grado para Optar al Grado de Licenciado en Lengua y Literatura Inglesas. Universidad de Chile: Facultad De 
Filosofía Y Humanidades Departamento De Lingüística. Retrieved 23 April 2020 from http://repositorio.uchile.cl/handle/2250/1376399

Alderson, J. (2000). Assessing reading. Cambridge: Cambridge University Press.

Ballance, O., \& Cobb, T. (2020). Resources for learning single-word items. In S. Webb (Ed.), The Routledge Handbook of Vocabulary Studies (pp. 320-335). Abingdon: Routledge.

Bax, S. (2013). Readers' cognitive processes during IELTS reading tests: evidence from eye tracking. ELT Research Papers 13-06. British Council. Retrieved 15 May 2020 from https://www.teachingenglish.org.uk/teacherdevelopment/publications/research-papers

Chacón-Beltrán, R. (2018). Vocabulary learning strategies outside the classroom context: what adults learn in a technology-based learner-centred environment. The Language Learning Journal, 46(5), 583-593.

Cobb, T. Compleat Web VP v.2.5 [computer program]. Accessed 18 Dec 2020 at https://www.lextutor.ca/vp/comp/

Demetriou, L. (2017). Selection, presentation and recycling of phrasal verbs in ESL textbooks in Cyprus. Paper presented at BAAL Vocabulary Special Interest Group conference, Reading, UK.

Drummond, A. (2018). Investigating the relationship between IELTS scores and receptive vocabulary size. Journal of the Foundation Year Network, 1, 113-125.

Dörnyei, Z. (2001). Motivational strategies in the language classroom. Cambridge: Cambridge University Press.

Elgort, I. (2011). Deliberate learning and vocabulary acquisition in a second language. Language Learning, 61(2), 367-413.

Ellis, N. (2001). Memory for language. In P. Robinson (Ed.), Cognition and second language instruction (pp. 33-68). Cambridge: Cambridge University Press.

File, K., \& Adams, R. (2010). Should vocabulary instruction be integrated or isolated?. TESOL Quarterly, 44(2), 222-248. 
Gardner, D. (2013). Exploring vocabulary. Language in action. Abingdon and New York: Routledge.

Green, A., \& Hawkey, R. (2011). An empirical investigation of the process of writing Academic Reading test items for the International English Language Testing System. In P. Thompson and L. Taylor (Eds.), IELTS Research Reports 11 (pp.273-374). Manchester: British Council.

Henriksen, B., \& Danelund, L. (2015). Studies of Danish L2 learners' vocabulary knowledge and the lexical richness of their written production in English. In P. Pietilä, K. Doró and R. Pípalová (Eds.), Lexical Issues in L2 Writing (pp. 29-56). Newcastle-upon-Tyne: Cambridge Scholars Publishing.

Hu, M., \& Nation, P. (2000). Unknown vocabulary density and reading comprehension. Reading in a Foreign Language, 3(1), 403-430.

IELTS (2020). Test taker performance 2019. Retrieved December 13, 2020, from https://www.ielts.org/research/test-taker-performancee

Laufer, B. (2003). Vocabulary Acquisition in a Second Language: Do Learners Really Acquire Most Vocabulary by Reading? Some Empirical Evidence. The Canadian Modern Language Review, 59(4), 567-587.

Laufer, B., \& Ravenhorst-Kalovski, G. (2010). Lexical threshold revisited: Lexical text coverage, learners' vocabulary size and reading comprehension. Reading in a Foreign Language, 22(1), 15-30.

Laufer, B., \& Shmueli, K. (1997). Memorizing new words: does teaching have anything to do with it? RELC Journal, 28(1), 89-108.

Lawley, J. (2010). Conspicuous by their absence: the infrequency of very frequent words in some English as a Foreign Language textbooks. In R. Chacón Beltrán, C. Abello-Contesse and M.M. Torreblanca-López (Eds.), Insights into nonnative vocabulary teaching and learning (pp.145-155). Bristol: Multilingual Matters.

Lin, P. (2012). Sound evidence: the missing piece of the jigsaw in formulaic language research. Applied Linguistics, 33(3), 342-347. 
Lin, P. (2019). Formulaic language and speech prosody. In A. Siyanova-Chanturia and A. Pellicer-Sánchez (Eds.), Understanding formulaic language. A secondlanguage acquisition perspective, (pp.78-94). New York: Routledge.

Little, D. (2003). Learner autonomy and second/foreign language learning. Subject Centre for Languages, Linguistics and Area Studies Good Practice Guide. Retrieved 14 March 2020 from https://www.llas.ac.uk/resources/gpg/1409

Martinez, R. and Murphy, V. 2011. "Effect of frequency and idiomaticity on second language reading comprehension". TESOL Quarterly, 45(2), 267-290.

Martinez, R., \& Schmitt, N. (2012). A phrasal expressions list. Applied Linguistics, 33(3), 299-320.

Milton, J. (2009). Measuring second language vocabulary acquisition. Bristol: Multilingual Matters.

Milton, J., Wade, J., \& Hopkins, N. (2010). Aural word recognition and oral competence in English as a Foreign Language. In R. Chacón Beltrán, C. AbelloContesse and M.M. Torreblanca-López (Eds.), Insights into non-native vocabulary teaching and learning, (pp. 83-98). Bristol: Multilingual Matters.

Nation, P. (2011). Research into practice: vocabulary. Language Teaching, 44(4), 529539.

Nation, P. (2013). Learning vocabulary in another language. Cambridge, UK: Cambridge University Press.

Nation, P., \& Webb, S. (2011). Researching and analyzing vocabulary. Boston, MA: Heinle/Cengage.

O'Loughlin, R. (2012). Tuning in to vocabulary frequency in coursebooks. RELC Journal, 43(2), 255-269.

Reinders, H., \& Lewis, M. (2006). An evaluative checklist for self-access materials. ELT Journal, 60(3), 272-278.

Schmitt, N. (2007). Current Perspectives on Vocabulary Teaching and Learning. In J. Cummins and C. Davidson (Eds.), International handbook of English language teaching (pp.827-841). New York: Springer. 
Schmitt, N. (2008). Review article. Instructed second language vocabulary learning. Language Teaching Research, 22(3), 329-363.

Schmitt, N. (2010). Researching vocabulary. Basingstoke: Palgrave-Macmillan.

Schmitt, N. (2013). Formulaic language and collocation. In C. Chapelle (Ed.), The Encyclopedia of Applied Linguistics (pp.1-10). Hoboken (NJ): Wiley-Blackwell.

Schmitt, N. (2014). Size and depth of vocabulary knowledge. What the research shows. Language Learning, 64(4), 913-951.

Schmitt, N. (2019). Understanding vocabulary acquisition, instruction, and assessment: A research agenda. Language Teaching, 52, 261-274.

Schmitt, N., Jiang, X., \& Grabe, W. (2011). The percentage of words known in a text and reading comprehension. The Modern Language Journal, 95(1), 26-43.

Schmitt, N., \& Schmitt, D. (2014). A reassessment of frequency and vocabulary size in L2 vocabulary teaching. Language Teaching, 47(4), 484-503.

Schmitt, N., \& Zimmerman, C. (2002). Derivative word forms: What do learners know? TESOL Quarterly, 36, 145-171.

Sökmen, A. (1997). Current trends in teaching second language vocabulary". In N. Schmitt and M. McCarthy (Eds.), Vocabulary. Description, acquisition and pedagogy (pp. 237-257). Cambridge: Cambridge University Press.

Tomlinson, B. (2010). Principles of effective materials development. In N. Harwood (Ed.), English language teaching materials: Theory \& practice (pp.81-109). Cambridge: Cambridge University Press.

Tomlinson, B., \& Masuhara, H. (2013). Survey revue: Adult coursebooks. ELT Journal, 67(2), 233-249.

Walter, C. (2008). Phonology in Second Language Reading: Not an Optional Extra. TESOL Quarterly, 42(3), 455-474.

Webb, S., \& Nation, P. (2017). How vocabulary is learned. Oxford: Oxford University Press.

Weir, C., Hawkey, R., Green, A., Unaldi, A., \& Devi, S. (2009). The relationship between the academic reading construct as measured by IELTS and the reading 
experiences of students in their first year of study at a British university. In P.

Thompson and L. Taylor (Eds.), IELTS Research Reports 9, Report 3 (pp.97156). Manchester: British Council.

Received: 10 June 2020

Accepted: 11 December 2020

Cite this article as:

Serrano van der Laan, M. (2020). Learning vocabulary for IELTS Academic Reading: An evaluation of some pedagogical materials. Language Value, 13(1), 78-102. Jaume I University ePress: Castelló, Spain. http://www.languagevalue.uji.es.

DOI: http://dx.doi.org/10.6035/LanguageV.2020.13.4

ISSN 1989-7103 